\title{
Primary infection by type 1 human immunodeficiency virus: diagnosis and prognosis
}

\author{
Philippe Vanhems, Raymond Beaulieu
}

\begin{abstract}
Summary
Primary infection by type 1 human immunodeficiency virus (HIV) is symptomatic in about $70 \%$ of cases. The acute illness is a mononucleosis-like syndrome with characteristics such as mucosal ulcerations. The duration and severity of the symptoms appear to be related to the prognosis. After reviewing the most frequent signs and symptoms of primary HIV infection, we report different prognostic studies which examined the association between the acute illness and the progression of HIV disease.
\end{abstract}

Keywords: HIV-1, primary infection, prognosis

\begin{tabular}{|l|}
\hline General manifestations \\
\hline - fever \\
- myalgia \\
- arthralgia \\
- asthenia \\
\hline
\end{tabular}

Box 1

\begin{tabular}{|l|}
\hline $\begin{array}{l}\text { Mucocutaneous manifesta- } \\
\text { tions }\end{array}$ \\
\hline - skin rash \\
- buccal ulcers \\
- genital ulcers \\
\hline
\end{tabular}

Box 2

\author{
Hôtel-Dieu de Montréal, University of \\ Montreal, Quebec, Canada \\ Research Centre \\ $P$ Vanhems \\ Department of Hematology \\ R Beaulieu
}

Correspondence to $\mathrm{P}$ Vanhems, Research Centre, Hôtel-Dieu de Montréal, Building Cooper, 3840 St-Urbain, H2W 1T8 Montreal, Quebec, Canada

Accepted 17 July 1996
Despite preventive interventions, transmission of type 1 human immunodeficiency virus (HIV) has not been controlled and the incidence of HIV infection has been estimated to be 40000 new cases per year in the US. ${ }^{1}$ These seroconversions are observed mainly among the young population, only $44 \%$ of which used condoms in 1991 compared to $56 \%$ in $1988 .^{2}$ In this same study, the proportion of young intravenous drug users was $2.1 \%$ in 1991 vs $0.5 \%$ in 1988. The risk of infection from unprotected sex and the growing consumption of intravenous drugs is worrisome, and these developments represent a serious failure of preventive campaigns.

More than half of infected persons will manifest clinical signs in the days following HIV infection. ${ }^{3}$ This initial stage of the disease was described for the first time in an isolated case in $1984,{ }^{4}$ followed by a series of patients reported by Australian researchers in $1985 .{ }^{5}$ Recently, the first controlled trial in which zidovudine was administered at the time of primary infection ${ }^{6}$ has been published, with beneficial results. The diagnosis of patients in this early stage is more than ever a necessity. The objective of this article is to review the clinical presentation and biological disturbances occurring during primary HIV infection and their relationship to prognosis. The studies cited are those with the most rigorous methodologies associated with pertinent results and published in reviews of internal medicine and infectious diseases sourced through MEDLINE.

\section{Epidemiology}

The symptoms of primary infection have been described in all populations at risk of HIV infection: homosexual men, heterosexual men and women, intravenous drug users, recipients of contaminated blood products, recipients of organs from infected donors, and accidentally infected workers in the healthcare sector. ${ }^{7}$ Until now, no study has reported on different clinical features according to risk factors. In $95 \%$ of cases, there is at least one clinical sign. ${ }^{1}$ Nevertheless, in the presence of mild symptoms or in their absence, seroconversion may pass completely unnoticed. Usually, the signs or symptoms of primary infection by HIV last for two to six weeks after contamination and persist, on average, for two weeks. These symptoms may become severe and require hospitalisation; $42 \%$ of patients were hospitalised in a recent Swiss study..$^{8}$

\section{Clinical manifestations}

The clinical manifestations are numerous but we will report the most frequent.

GENERAL MANIFESTATIONS (Box 1)

In the series reported by Kinloch $e t a l,{ }^{8} 87 \%$ of patients had fever whereas only $53 \%$ of those in the series of Pedersen $e t a l^{9}$ presented this symptom. The average temperature was $38.6^{\circ} \mathrm{C}$, and eight out of 27 patients had a temperature over $39^{\circ} \mathrm{C} .{ }^{8}$ Myalgias and arthralgias sometimes accompanied the fever. The mean duration of these symptoms was 16 days $^{9}$ and 23 days. ${ }^{8}$ Persistence of symptoms for more than 14 days seemed to be related to a poor prognosis. ${ }^{9}$

\section{MUCOCUTANEOUS MANIFESTATIONS (Box 2)}

A skin rash is present in more than $60 \%$ of cases (figure 1 ). ${ }^{8}$ These eruptions are erythaematous, maculopapular, nonpruriginous, and usually symmetrical. They affect the face, trunk and sometimes the extremities, but generalised eruptions are rare. ${ }^{10}$ Vesicular lesions have also been reported. ${ }^{11}$

Mucosal ulcerations are frequently reported: $43 \%$ in the series of Kinloch $e t$ $a l .{ }^{8}$ They are localised in the oral cavity, sometimes associated with tonsillitis, 
Figure 1 Severe abdominal skin rash during an acute HIV disease

Figure 2 Genital ulcer during an acute HIV disease

\begin{tabular}{|l|}
\hline Neurological manifestations \\
\hline - headache \\
- retro-orbital pain \\
- photophobia \\
- meningitis \\
- radiculopathy \\
- depression \\
\hline
\end{tabular}

Box 3
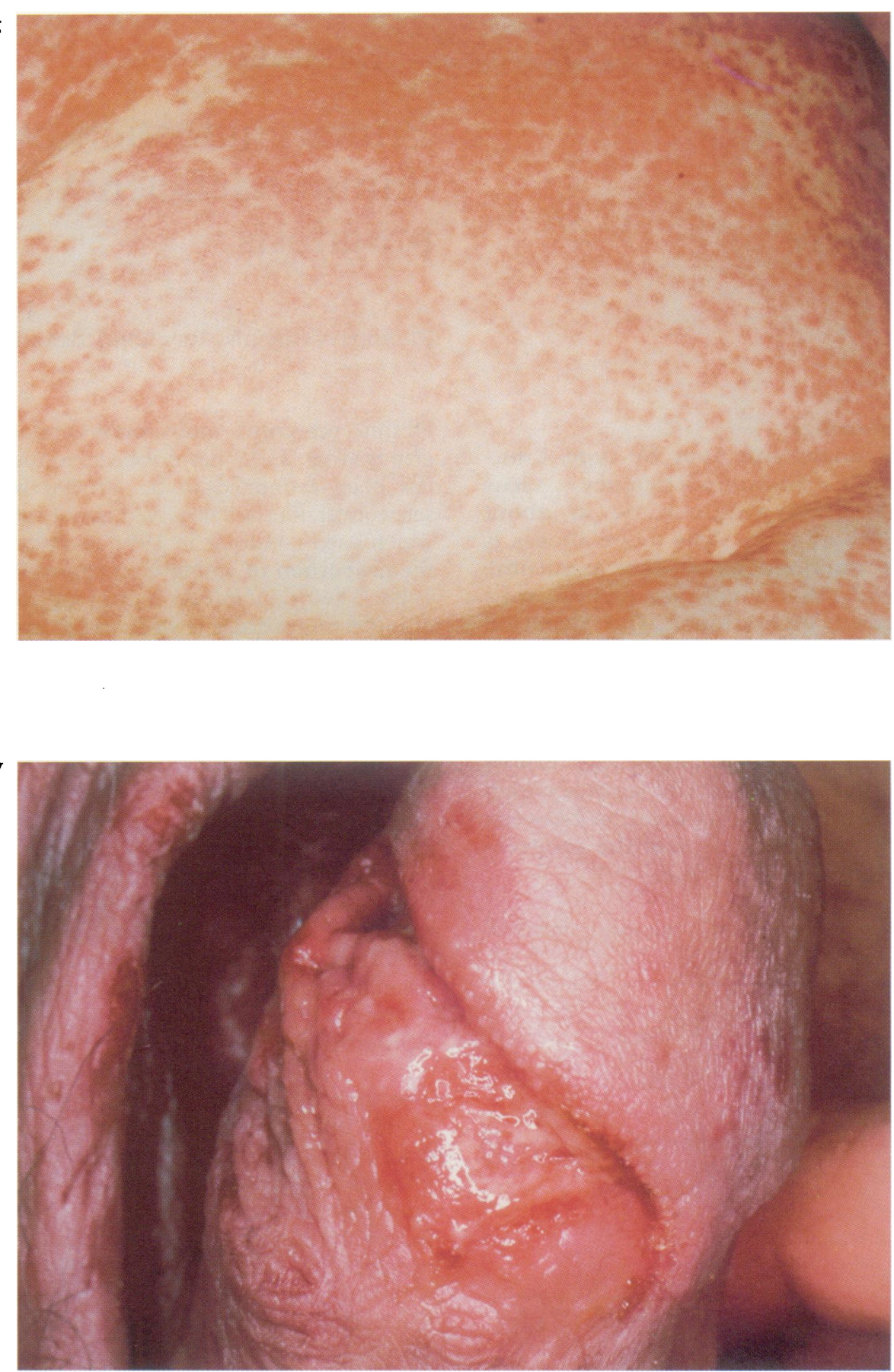

and on the genital organs (figure 2). In the same series, none of the patients infected by the parenteral route presented with mucosal ulcers whereas $52 \%$ of sexually infected subjects did. Gaines $e a^{12}$ found similar results in seven out of 20 homosexual men, indicating that ulcers may be the site of viral inoculation during sexual intercourse. Of patients presenting cutaneous lesions, $52 \%$ also manifest mucosal lesions, whereas $84 \%$ of subjects presenting mucosal lesions also manifest cutaneous lesions. ${ }^{8}$ The association of these lesions thus strongly suggests primary HIV infection because of the limited number of differential diagnoses.

\section{LYMPH NODE MANIFESTATIONS}

Adenopathies are present in more than $50 \%$ of cases. ${ }^{7,8}$ They are usually not painful, but may be generalised or localised.

\section{NEUROLOGICAL MANIFESTATIONS (Box 3)}

HIV has been isolated from cerebrospinal fluid in primary infection, indicating the early involvement of this system. The most frequent neurologic symptoms are headache, retro-orbital pains and photophobia. Depression, irritability and mood swings may also be observed, suggesting early involvement of affective 


\begin{tabular}{|l|}
\hline Gastrointestinal \\
manifestations \\
\hline - transit disturbances, anorexia, \\
nausea, diarrhoea \\
- oral candidiasis \\
- oesophageal candidiasis \\
\hline
\end{tabular}

Box 4

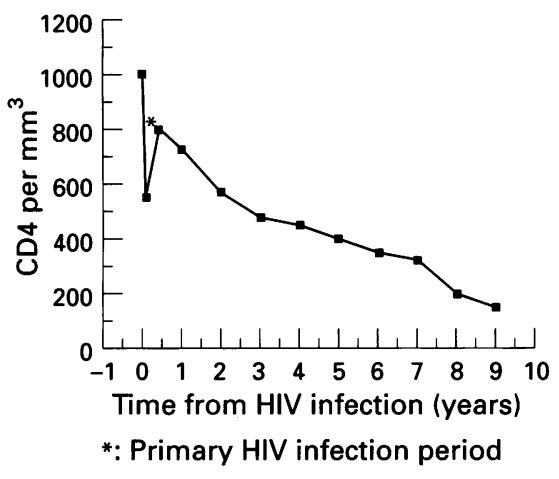

Figure 3 Pattern of $\mathrm{CD}^{+} \mathrm{T}$ cell count during HIV infection (figure adapted from during

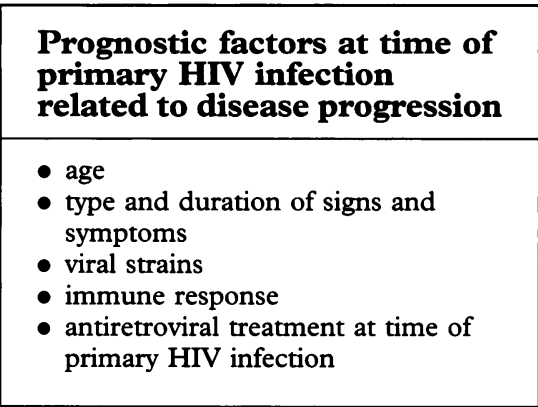

Box 5 functions, ${ }^{10}$ but depression is most often associated with announcement of the diagnosis. Other neurologic symptoms, such as meningitis or radiculopathy, are sometimes observed but they are less common. ${ }^{8,11}$

\section{PULMONARY MANIFESTATIONS}

Pulmonary manifestations are not frequent. Patients may present with a dry cough, most often associated with nonspecific interstitial pneumopathy.,

\section{GASTROINTESTINAL MANIFESTATIONS (Box 4)}

Nonspecific digestive symptoms such as anorexia, nausea and diarrhoea have been reported. The most suggestive signs of immune deficiency, such as oral and/or oesophageal candidiasis, have also been observed in association with severe transient immunosuppression. ${ }^{7,9}$ Oral candidiasis and oral hairy leukoplakia may appear relatively soon after seroconversion since the cumulative proportion of patients presenting these complications is $12 \%$ at one year and $30 \%$ at three years. ${ }^{13}$ Such observations are important because these two types of buccal lesions are associated with a higher risk of developing acquired immunodeficiency syndrome (AIDS). ${ }^{13}$

\section{Biological disturbances}

Transient lymphopenia of helper $\mathrm{T}$ lymphocytes or $\mathrm{CD}^{+}$has been observed (figure 3), followed by lymphocytosis due to an elevation of cytotoxic $T$ lymphocytes or $\mathrm{CD}^{+} .{ }^{14}$ Thrombocytopenia is also a frequent anomaly. ${ }^{8,10} \mathrm{It}$ is usually moderate, mostly about $145 \times 10^{9} / 1$. An increase in the erythrocyte sedimentation rate has also been reported. ${ }^{10}$ The primary HIV infection is accompanied by activation of the immune and inflammatory system which results in an elevation of $\beta 2$-microglobulin, neopterine and $\alpha$-interferon. The number of $\mathrm{CD}^{+}$lymphocytes increases, while there is a decrease of helper $\mathrm{CD}^{+} \mathrm{T}$ lymphocytes with a persistent inversion of the $\mathrm{CD}^{+} / \mathrm{CD}^{+}$ratio within the first year of HIV infection. ${ }^{14}$ The mean blood level of $\mathrm{CD}^{+}$, measured six months before seroconversion, was $0.999 \times 10^{9} / 1$ whereas it was a maximum of $0.349 \times 10^{9} / 1$ one year after seroconversion. ${ }^{14}$

Frequently, detection of HIV antibodies by the usual techniques (ELISA) is negative when symptoms are present, so that it is necessary to repeat the test after a few days or even weeks to confirm seroconversion. On the other hand, the symptoms coincide with significant viral load confirmed by a strong transient viraemia, an increase of the viral antigen p24 and an elevated titre of provirus in mononuclear cells from peripheral blood. ${ }^{15,16}$ In $76 \%{ }^{8}$ to $90 \%{ }^{6}$ of patients, p24 antigen is present between the 6th and 15th day after the first appearance of symptoms, then becomes undetectable between the 14 th and 27 th day. ${ }^{8}$ Quantification of viral genome circulating in plasma now permits the evaluation of viral load ${ }^{15,16}$ in the primary infection stage and is a good reflection of the quantity of circulating virus. The decrease of p24 antigen and other viral particles in blood is the result of the patient's initial humoral immunologic response, of an increased number of cytotoxic $\mathrm{CD}^{+} \mathrm{T}$ lymphocytes and the sequestration of the virus in secondary lymphoid organs such as lymph nodes. 17

\section{Prognosis (box 5)}

\section{AT THE TIME OF THE PRIMARY HIV INFECTION}

\section{Age}

Age at the time of seroconversion seems to influence the AIDS incubation period since haemophiliac children develop AIDS more slowly than adult haemophiliacs. ${ }^{18}$ An Italian study of intravenous drug users with seroconversion confirmed that an advanced age at the time of seroconversion was associated with a poor prognosis ${ }^{19}$; these results were confirmed by cases infected by the sexual route. ${ }^{20}$

\section{Presence and duration of symptoms}

A study of 48 patients with seroconversion (19 symptomatic and 29 asymptomatic) showed that evolution towards AIDS and/or a $\mathrm{CD}^{+}$level below $0.200 \times 10^{9} / 1$ was faster in symptomatic patients. ${ }^{21}$ Nevertheless, arbitrary classification between symptomatic and asymptomatic patients is difficult since mild symptoms may sometimes be overlooked. It appears more realistic to classify patients according to a scale of severity or duration of symptoms rather than their presence or absence. According to Pedersen et al, ${ }^{9}$ the risk of developing AIDS three years after seroconversion is eight times 
Summary/learning points

- primary HIV infection is symptomatic in nearly $70 \%$ of cases

- signs and symptoms are similar to mononucleosis but various clinical features may occur

- type, duration and severity of clinical features are related to HIV disease progression

- antiretroviral treatment at time of primary HIV infection seems to have a beneficial impact on prognosis

Box 6 greater for persons with symptomatic primary infection lasting more than 14 days. Progression to group IV complications (according to the CDC definition $^{22}$ ) is also more rapid in this group $(78 \%$ vs $10 \%)$. It thus appears that immunologic and viral factors associated with the progression of the disease play an important role at this stage. However, numerous questions are still unanswered: What is the influence of immunologic status of the patient before infection on the duration of symptoms? What is the impact of symptomatic treatment on the duration and severity of symptoms? What is the role of preexisting genital mucosal ulcerations which may facilitate infection and permit penetration by a significant viral inoculum?

According to a Dutch study, ${ }^{23}$ the presence of fever and cutaneous eruptions at the time of seroconversion has been associated with a more rapid progression towards AIDS. This study confirmed the relationship between the severity of symptoms in the course of seroconversion but only two symptoms were analysed.

\section{Viral strains}

Roos et $a l^{24}$ undertook a prospective study of viral and immunologic parameters in 19 patients with seroconversion. Three patients were infected by viral strains inducing multinucleated cells or syncytia after cell culture. In these three cases, diminution of $\mathrm{CD}^{+}$was most rapid, and two of them presented AIDS at six and 19 months, respectively. In 15 patients out of 16 infected by strains not inducing the formation of syncytia, the $\mathrm{CD}^{+}$level was normal at the end of follow-up (average 391 days) and the patients remained asymptomatic. In two patients infected by a viral strain inducing syncytia, the same viral phenotype was found in the contaminating individual, confirming the possibility of transmission of these viral strains. Recently, the transmission of viral strains resistant to zidovudine was associated with more rapid progression of the disease. $^{25}$

Viral and immunologic markers

Schechter $e t a l^{26}$ performed a prospective study of 18 subjects who developed AIDS in a cohort of homosexual patients in whom the date of seroconversion was known. Four months before seroconversion, these patients presented a decrease of $\mathrm{CD}^{+}$, a lower $\mathrm{CD} 4^{+} / \mathrm{CD}^{+}$ratio, a diminution of haemoglobin, an elevation of $\operatorname{IgA}, \operatorname{IgG}$ and circulating immune complexes compared to 54 patients with seroconversion but who had not progressed to AIDS. In 84 subjects with seroconversion in the Multicenter AIDS-Cohort study, an American prospective study which included only homosexual patients, 18 developed AIDS within 36 months. Neither the level of p24 antigen nor the level of anti-p24 antibodies was associated with progression to AIDS. ${ }^{27}$ Patients who had developed AIDS by 36 months had significantly higher $\mathrm{CD}^{+}$levels $\left(>0.400 \times 10^{9} / 1\right)$ at the time of seroconversion than those who did not evolve to AIDS. Lifson et $a l^{28}$ undertook a prospective study of the immunologic characteristics of 24 homosexual patients who did not progress to AIDS in nine years in comparison with patients who developed AIDS and HIV-negative patients. An elevated level of $\beta 2$-microglobulin and $\mathrm{CD}^{+}$at the time of seroconversion was associated with a favourable prognosis among those whose disease did not progress. In the study cited above, ${ }^{22}$ the absence of secretion of anti-HIV antibodies of the anti-p24 type and the presence of p24 antigen are independent predictors of a more rapid progression of the disease.

\section{Concomitant infections}

Do concomitant infections influence the evolution to AIDS? Cytomegalovirus and Epstein-Barr virus, which are common in the general population, themselves induce immunosuppression. It is thus possible that the pathogenic effects of each virus are potentiated. However, co-infection with other infectious agents such as hepatitis B or C virus, Treponema pallidum or type 2 herpes simplex virus has not proven, up to now, to worsen the prognosis.

Impact of treatment of primary infection with antiretroviral agents

Trials on the use of zidovudine in the asymptomatic or slightly symptomatic stages have given contradictory results. ${ }^{29}$ Nevertheless, treatment of the primary infection stage has been shown to be warranted. ${ }^{30}$ For this reason, two controlled trials have been conducted, of which one is ongoing and the other has been published. ${ }^{6,31}$ Patients received either $500 \mathrm{mg} /$ day of zidovudine or placebo for six months; 15 months after inclusion, the treated group presented significantly less opportunistic infections with a higher $\mathrm{CD} 4^{+}$count than the placebo group (values at the limit of significance). Prospective follow-up of these patients will allow long-term evaluation of zidovudine. However, early 
prescription of antiretroviral treatment may lead to the rapid emergence of resistant viral strains, notably to zidovudine, which may then be transmitted from one patient to another. ${ }^{32}$ We ignore, for the moment, the question of whether contamination by this type of viral strain modifies the clinical presentation of the primary infection and whether the strain may again become sensitive to zidovudine in the absence of its administration.

\section{PRIOR TO THE PRIMARY HIV INFECTION}

Why do certain patients manifest symptomatic primary infection? Are there predisposing factors or a particular susceptibility to HIV infection? Little is known about this. The stage of the disease in the person who infects his or her partner appears to have an impact. Patients infected by the administration of contaminated blood products present symptomatic primary infection more frequently when donors develop AIDS within 29 months of the donation. ${ }^{33}$ Similarly, the recipients progress to a symptomatic stage more rapidly when the donor quickly develops AIDS. These observations coincide with studies on circulating viral load which demonstrated a larger quantity of virus in blood in the advanced stage of the disease. ${ }^{15}$ Nevertheless, recent investigations have shown that the quantity of circulating virus is important in the asymptomatic stages as well. ${ }^{15}$ The hypothesis of genetic predisposition linked, for example, to a certain type of major histocompatibility antigen (HLA) which induces rapid diminution of $\mathrm{CD}^{+}$is appealing, but the results remain contradictory, notably for the HLAs DR2, DR3 and DR5. ${ }^{30,34,35}$ The HLA phenotypes A1, Cw7, B8 and DR3 meanwhile appear to be associated in a significant way with a more rapid decrease of $\mathrm{CD4} 4^{+}, 30$ while the HLA phenotype DR2 seems to be frequently accompanied by the presence of p 24 antigen in the blood. ${ }^{34}$

\section{Conclusion}

The symptoms and signs of primary HIV infection are now better understood, and all physicians, whether they are general practitioners or specialists, should recall this diagnosis in persons presenting clinical manifestations of acute infectious disease and at risk of HIV infection. The search for viral load, p24 antigen, associated with antibodies, are essential, since most of the time, antibodies are undetectable at this stage of infection. Tests to detect antibodies should be repeated to confirm seroconversion. Biological investigations will nevertheless permit the exclusion of other possible diagnoses. The prescription of zidovudine or other antiretroviral medications at this stage has not proven their long-term efficacy against the development of AIDS and survival. Nevertheless, the results of a recent controlled clinical trial have demonstrated a beneficial effect of zidovudine on the $\mathrm{CD}^{+}$count with a reduction in the incidence of opportunistic infections after an average follow-up of 15 months. ${ }^{6}$

Our thanks to Professor B Hirschel (Geneva) for providing figure 2.

Philippe Vanhems is supported by the National Swiss Foundation for Scientific Research (Grant \#823B-033270) and the Canadian HIV Trials Network-Quebec Region and the Fonds de la Recherche en Santé du Quebec (Etude primo-infection au VIH).

1 Niu MT, Stein DS, Schnittman SM. Primary human immunodeficiency virus type 1 infection: review of pathogenesis and early treatment intervention in human and animal retrovirus intervention in human and animal retrovir $2 \mathrm{Ku} \mathrm{L}$, Sonenstein FL, Pleck JH. Young men's risk behaviors for HIV infection and sexually transmitted diseases, 1988 through 1991. Am $\mathcal{J}$ Public Health 1993; 83: 1609-15.

3 Tindall B, Barker S, Donovan B, et al. Characterization of the acute clinical illness associated with human immunodeficiency virus infection. Arch Intern Med 1988; 148: 945-9.

4 Anonymous. Needlestick transmission of HTLV-III from a patient infected in Africa (editorial). Lancet 1984; 2: 1376-7.

5 Cooper DA, Gold J, MacLean P, et al. Acute AIDS retrovirus infection: definition of a clinical illness associated with seroconversion. Lancet 1985; 1: 537-40.

6 Kinloch-de Loes S, Hirschel BJ, Hoen B, et al. A controlled trial of zidovudine in primary human controlled trial of zidovudine in primary human immunodeficiency vir.

7 Clement $M$, Hollander $H$. Natural history and managment of the seropositive patient. In: Sande MA, Volberding PA, eds. The medical managment of AIDS. Philadelphia: WB Sanders, 1992; pp 87-96.
8 Kinloch-de Loës S, de Saussure P, Saurat JH, Stalder H, Hirschel B, Perrin LH. Symptomatic primary infection due to human immunodeficiency virus type 1: review of 31 cases. Clin Infect ciency virus type 1: re

9 Pedersen C, Lindhart BO, Jensen BL, et al. Clinical course of primary HIV infection: consequences for subsequent course of infection BMF 1989; 299: 154-7.

10 Tindall B, Imrie A, Donovan B, Penny R, Cooper DA. Primary HIV infection. In: Sand MA, Volberding PA, eds. The medical manag ment of AIDS. Philadelphia: WB Sanders, 1992; pp 67-86.

11 Calabresse LH, Proffitt MR, Levin $\mathrm{KH}$, et al. Acute infection with the human immunodeficiency virus (HIV) associated with acute brachial neurotis and exanthematous rash. Ann Intern Med 1987; 107: 849-51.

12 Gaines H, von Sydow M, Pehrson PO, LundberghP. Clinical picture of primary HIV infection presenting as a glandular-fever-like illness. tion presenting as a glan

13 Lifson AR, Hilton JF, Westenhouse JL, et al. Time from HIV seroconversion to oral candidiasis or hairy leukoplakia among homosexual and bisexual men enrolled in three prospective cohorts. AIDS 1994; 8: 73-9.
14 Stein DS, Korvick A, Vermund SH. CD4 lymphocyte cell enumeration for prediction of clinical course of human immunodeficiency virus disease: a review. $\mathcal{f}$ Infect Dis 1992; 165: 352-63.

15 Piatak M, Saag MS, Yang LC, et al. High level of HIV-1 in plasma during all stages of infection determined by competitive PCR. Science 1993 259: 1749-54

16 Baumberger C, Kinloch-de-Loes S, Yerly S, Hirschel B, Perrin L. High levels of circulatin RNA in patients with symptomatic primary HIVinfection. AIDS 1993; 7(S2):S59-S64.

17 Pantaleo G, Fauci AS. New concepts in the immunopathogenesis of HIV infection. Annu Rev Immunol 1995; 13: 487-512.

18 Biggar RJ and the International Registry of Seroconverters. AIDS incubation in $1891 \mathrm{HIV}$ seroconverters from different exposure groups. AIDS 1990; 4: 1059-66

19 The Italian Seroconversion Study. Disease progression and early predictors of AIDS in HIV-seroconverted infecting drug users. AIDS 1992; 6: 421-6.

20 Carre N, Deveau C, Belanger, et al. Effect of age and exposure group on the onset of AIDS in heterosexual and homosexual HIV-infected patients. AIDS 1994; 8: 797-802. 
21 Lindback S, Brostrom C, Karlsson A, Gaines H. Does symptomatic primary HIV-1 infection accelerate the progression to CDC stage IV
disease, CD4 count below $200 \times 10^{6} / 1$, AIDS, and death from AIDS? BMF 1994; 309: 1535-7.

22 Update: acquired immunodeficiency syndromeUnited States. MMWR 1987; 36: 522-6.

23 Keet IPM, Frijnen P, Koot M, et al. Predictors of rapide progression to AIDS in HIV-1 serof rapide progression to AIDS in

24 Roos MTL, Lange JMA, Goede REY, et al. Viral phenotype and immune response in primary human immunodeficiency virus type 1 infection. f Infect Dis 1992; 165: 427-3

25 Richman DD. Resistance, drug failure, and disease progression. AIDS Res Hum Retroviruses 1994; 10: 901-5.

26 Schechter MT, Craib KJP, Le TN, et al. Susceptibility to AIDS progression appears early in HIV infection. AIDS 1990; 4: 185-90.

27 Farzadegan $\mathrm{H}$, Chmiel JS, Odaka N, et al. Association of antibody to human immunodeficiency virus type 1 core protein (p24), CD4 lymphocyte number, and AIDS-free time. $\mathfrak{f}$ lymphocyte number, and AID
Infect Dis 1992; 166: 1217-22.
28 Lifson AR. Buchbinder SP, Sheppard, et al. Long-term human immunodeficiency virus infection in asymptomatic homosexual and bisexual men with normal CD4+ lymphocyte counts: immunologic and virologic characteristics. $\mathcal{f}$ Infect Dis 1991; 163: 959-65.

29 Cooper DA. Early antiretroviral therapy. AIDS 1994; 8: S9-S14.

30 Kaslow RA, Duquesnoy R, VanRaden $M$, et al. A1, Cw7, B8, DR3 HLA antigen combination associated with rapid decline of $T$-helper lymassociated with rapid decline of T-helper lymphocytes

31 Niu MT, Stein DS, Schnittman SM. Treatment trials for primary human immunodeficiency virus type 1 infection. F Infect Dis 1993; 168: 1601-2.

32 Erice A, Mayers DL, Strike DG, et al. Brief report: primary infection with zidovudine-resistant human immunodeficiency virus type $1 . N$ Engl f Med 1993; 328: 1163-5.
33 Ward JW, Bush TJ, Perkins HA, et al. The natural history of transfusion-associated infection with human immunodeficient virus. $N$ Eng f Med 1989; 321: 947-52.

34 Fabio G, Marchini M, Scorza Smeraldi R, et al. Possible association of HLA-DR2 phenotype and detectable human immunodeficiency virus (HIV) p24 antigen in HIV positive patients. $\mathcal{F}$ Infect Dis 1993; 167: 499-500.

35 Itescu S, Brancato LJ, Buxbaum, et al. A diffuse infiltrative CD8 lymphocytosis syndrome in infiltrative CD8 lymphocytosis syndrome in a host immune response associated with HLAa host immune response associated with

36 DR5. Ann Intern Med 1990; 112: 3-10. Fauci AS. Immunopathogenes

37 Stein DS, Korvick JA, Vermund SH. CD4 lymphocyte cell enumeration for prediction of clinical course of human immunodeficiency virus disease: a review. F Infect Dis 1992; 165: $352-63$

\section{Medical Anniversary \\ CLAUDE BERNARD, 12 July 1813}

Claude Bernard (1813-78) was born at St Julien in the wine-producing Beaujolais area of France, where his parents toiled in the vineyards. He qualified in medicine in Paris (1839) and became a professor at the Collège de France and Hôtel Dieu, succeeding professor of anatomy Magendie.

Claude wrote voluminously on biology and physiology, particularly on gastric juice in nutrition, curare, carbohydrate metabolism, the pancreas and the liver, and he isolated glycogen in 1857. Ill-health forced him to spend much time at his old home St Julien, where he had bought the manor house where his parents' employer had lived. He became president of the Académie Francaise, and was the first French scientist to receive a national funeral in 1878. - DG fames 